Article

\title{
The Network of Protected Areas (NPA) as an Instrument to Implement Cross-Border Public Services
}

\author{
Maria Coronato * and Maria Prezioso * \\ Department of Management and Law, University of Rome, 00133 Rome, Italy \\ * Correspondence: maria.coronato@uniroma2.it (M.C.); maria.prezioso@uniroma2.it (M.P.)
}

Received: 5 August 2019; Accepted: 27 August 2019; Published: 3 September 2019

check for updates

\begin{abstract}
Polycentric development, territorial cohesion, and territorial diversity are some of the main principles supported at the European level for reducing regional disparities and for making territories more resilient and diversified, which strengthens the competitiveness of Europe in the global economy. This research article, starting from the final results of the ESPON Linking Networks of Protected Areas to Territorial Development (LinkPAs) project, considers that the protected areas (PAs) are a territorial unit able to connect-in a polycentric approach-the different territorial aspects (economic, social, environmental) present in an area to implement cross-border public services (CPS) to share in a larger territorial context through a network of protected areas (NPA). Toward this aim, this paper suggests applying the NPA management model developed in the ESPON LinkPAs project to CPS to assess if a soft governance mechanism is able to efficiently and sustainably manage the CPS.
\end{abstract}

Keywords: network of protected areas; polycentric development; green infrastructures; territorial development; territorial cohesion; cross-border services

\section{Introduction}

The extension of protected areas in Europe is very large, and it has been investigated by the ESPON "Linking Networks of Protected Areas to Territorial Development" (LinkPAs) project. The evidence shows that the PAs are the "backbone" of the EU green infrastructures (GIs) strategy supporting the ecosystem services, green economy policies, and climate change mitigation.

Protected areas (PAs) management and territorial development strategies generally appear integrated into planning tools (in accordance with national/regional legislation) as well as the GI. According to a functional and polycentric approach, the PAs act as a pole of development within a larger area that need to be managed by a network. The PAs, organized in a network, are configurated as a network of protected areas (NPA).

The soft governance mechanism for the NPAs developed in ESPON LinkPAs is able to go over the administrative and political borders of PAs (limit of territorialism) [1]. This final result is implemented here, looking at cross-border public services (CPS) (e.g., tourism, transport, healthcare, education, etc.) to share at international, national, and subnational levels.

Toward this aim, this paper considers the protected areas as territorial units for territorial development, and stresses the need to use the natural (territorial) border to better identify the specific territorial needs. Finally, the NPA management model developed in the LinkPAs project [2] will be linked to CPS to arrive at some general remarks and suggestions. 


\section{The Protected Areas as Territorial Units for Territorial Development}

According to the Action Plan of the EU Commission, the PAs could be the main actors to apply, at the local level, the actions/strategies able to achieve the European goals, particularly regarding biodiversity conservation. Davoudi (2019) [3] suggest that "Designing for borderless areas creates new grounds for cooperation at all levels, bringing people and places closer together to find joint solutions for their well-being". New types of cooperation (formal or unformal) combined with soft governance mechanism are able to achieve economic, social, and environmental goals in a simpler way. Is crucial to improve the interest of local stakeholders, stressing socio-economic interactions between PAs and territories as well as between PAs and cities. In this way, it is possible to overcome the old approach of the "insularization" of PAs: protected areas are part of the economic and social process, and cannot be left out of the development strategies. Therefore, it is necessary to include PAs in the planning process establishing rules and aims. If well-managed, protected areas could effectively contribute to generate added value at the local level while also improving residents' quality of life. In addition, PAs are able to maintain several aspects (natural, economic, social) that represent the real natural and landscape richness of the context. In fact, PAs are characterized by a high level of supply of ecosystem services, and they present a great potential for the implementation of green economy and climate change mitigation policies. Tourism, agriculture, wellness, and education are some of the economic sectors implemented in PAs. On the other hand, PAs are characterized by low population density, elderly population, and poor physical accessibility. This last aspect is the main factor that limits the development of PAs. Thus, improving accessibility and territorial cooperation and reducing isolation are crucial. Toward this end, it is necessary to develop/strengthen links between the protected areas and the larger territories in which they belong, generating connections, more or less flexible, supported by polycentric strategies and soft governance mechanisms able to match aims and strategies at the macroregional level (over the border) to produce non-controversial cooperative planning with local communities. Local communities play a central role with regard to the knowledge of the territorial need in and around PAs that could be satisfied through sharing CPS.

Overcoming the PA borders means supporting the interactions (within a specific PA and between PAs) among natural and cultural components; for example, improving the bio-connectivity within a specific PA. In this way, the interactions between PAs are fundamental in terms of ecological connectivity/ecological networks that today represent a serious treatment of biological diversity and ecological processes [4], through the creation of a physical network of core areas and buffer zones [5]. In this sense, PAs are part of a wider territorial network, over and trans-border, and represent stepping stones in an innovative governance perspective able to connect PAs of different typologies [6].

In Europe, the extension of PAs is very large (Figure 1). According to EU experience and the EU Action Plan, PAs are often not confined within an administrative border area: the management of PAs is often in the competence of more than one institutional public actor (e.g., the Alps region), and each actor has a different and specific role. This is important to consider for spatial planning: ecoservices and cultural services, as well as economic and policy sectors, where PAs have an impact (e.g., energy, climate change mitigation, transport, education, etc.) [2] need to be analyzed at one time in the whole process.

This approach places the concept of territory at the center of European policy by looking at local specificities (territorial diversity), integrating administrative boundaries and thematic competence with elements of territorial continuity and/or diversity (e.g., settlement types, geographical and natural aspects). This becomes even more important when looking at environmental aspects associated, for example, with climate change, flooding, biodiversity loss, or pollution, which require a response to a different geographical scale, in some cases involving cooperation between neighboring regions. Here, the PAs become a territorial unit for territorial development. 


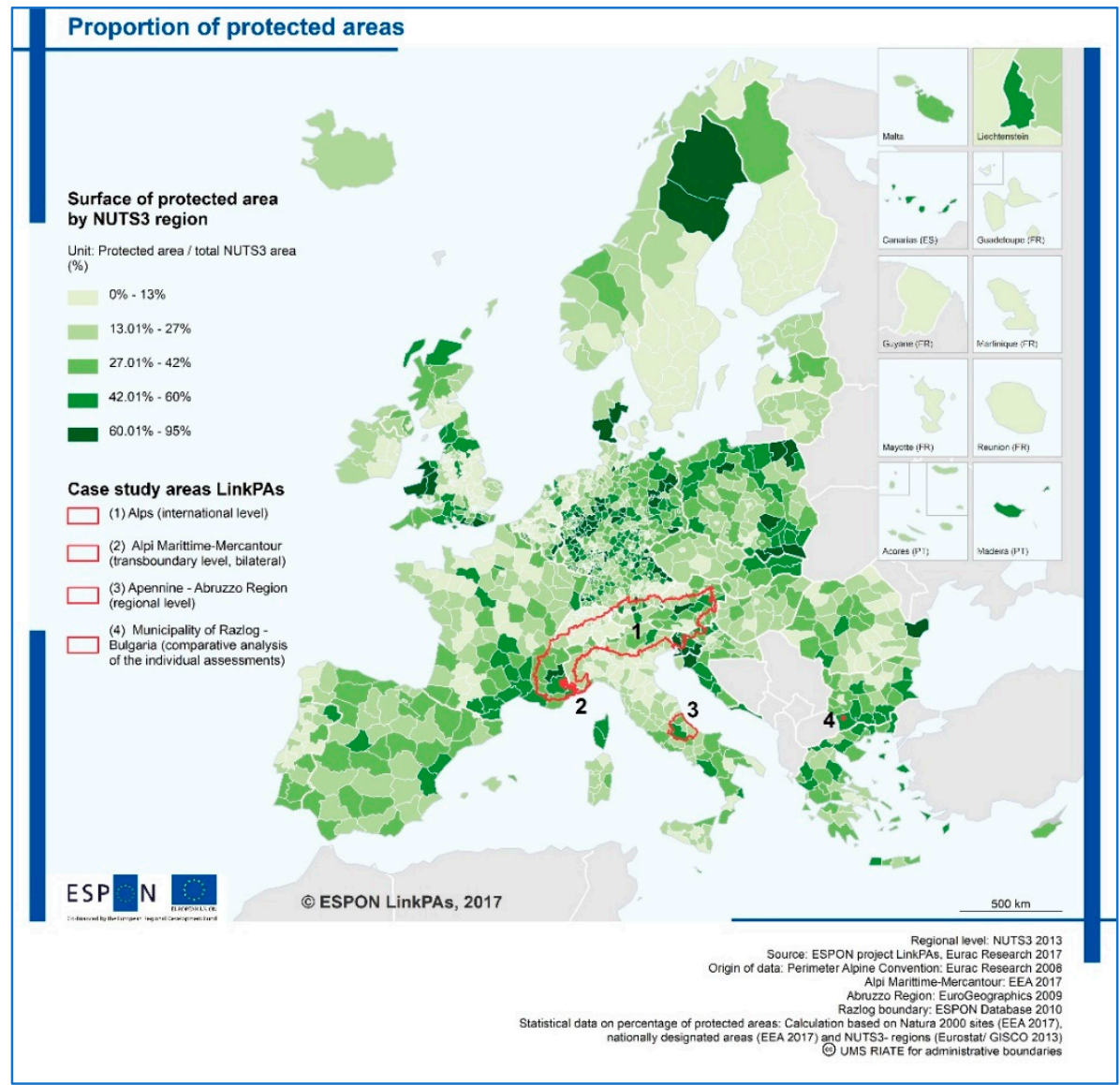

Figure 1. Proportion of protected areas. Source: ESPON LinkPAs, Final Main report, 2018, p. 2.

Toward this scope, the European Union is pushing towards polycentrism and territorial cooperation (seeking territorial cohesion) for a flexible sharing of services (e.g., CPS) among borders and territories, supporting the establishment of a network (of protected areas) also formalized within the European Grouping of Territorial Cooperation (EGTC) [7] able to increase the level of cohesion (territorial, economic, and social) and to implement actions of integrated sectoral policies at European and transnational levels.

\section{The Polycentric Approach in the Protected Areas to Implement Cross-Border Public Services}

In a polycentric approach, each PA works focusing on its own territorial capital and, if PAs build a network of protected areas, the final value of the area is increased. In this framework, the PAs, organized as an NPA, become a territorial unit able to connect the local dimension (territorial capital) to the political and sectoral dimensions.

The EU considers polycentrism as the basis of balanced territorial development [8]. The polycentrism does not require massive economic investments, but a polycentric organization pushes, strengthens, and supports the construction of links with neighboring territories by sharing the individual resources to more efficiently manage functions and services.

The regionalization of policies and the growing weight of the relative institutions is accompanied by the emergence of so-called multi-level governance. Multilevel governance and the polycentric approach support the development of regional policies towards a closer relationship with the territorial dimension, increasing the territorial cohesion. Territorial cohesion, based on territorial diversity, is able to guide toward EU policy objectives [9]. Territorial diversity does not modify the territorial models but supports the territorial systems, based on territorial capital (within PAs), through a 
polycentric territorial cooperation mechanism organized on the basis of innovative planning and management tools.

In the framework of biodiversity conservation and sustainable development, recent European experiences [2] have highlighted different legislative, planning, management, and governance approaches regarding protected areas also belonging to the same IUCN categories.

Following the evolution of different approaches to biodiversity conservation and sustainable development, protected areas management is currently included within an ecological network approach [10]. These approaches are even more complex if the territorial development is based on a systemic approach that supports a spatial planning process integrated in a network mechanism, in particular for the mitigation and adaptation to climate change and, of course, for the protection of biodiversity. In this framework, as part of territorial planning, the GIs organize and manage the territorial development system in which the protected areas are development poles.

Starting from this point of view, PAs are being designated and managed as systems, rejecting the traditional view that regards protected areas as "islands of nature", fenced off from the dangerous outside world. Contrariwise, within an ecological network approach, PAs appear as active stakeholders able to polycentrically integrate territorial capital into territorial strategies and plans so as to increase territorial cohesion.

The Action Plan of the EU Commission [11], devoted to reaching the EU 2020 goals on biodiversity, identifies the following as its priority: "ensuring better coherence of biodiversity conservation with broader socio-economic objectives" [12]. In order to achieve this aim, in many cases, the PAs organized in NPAs become a governance instrument to support the green infrastructure strategy. The territorial evidence shows that the PAs organized in NPAs are able to valorize the territorial capital starting from territorial diversity: a polycentric development approach built on network of protected areas contributes to reducing territorial disparities, increases territorial cohesion, and makes territories more resilient.

However, when applied to cities and regions, the polycentric development strategies planned on the networks have administrative boundaries and identify specific (political and sectoral) roles. In contrast, the boundaries of the protected areas are not defined, because the PAs have natural borders that could be in the competence of two or more administrative areas (e.g., Alps regions) with different actors and aims. For this reason, it is necessary to plan protected areas at the macroregional level, stressing cross-border cooperation and flexible governance mechanism. The role of networks (in general and of PA in particular) is crucial in this approach, and as Feldman said in 2012 [13]: "Network performance has three vital functions for environmental issues: (1) generate and disseminate information, (2) undertake effective policy evaluation strategies, (3) initiate response efforts local, without waiting for national efforts (both formal and informal)". Therefore, the network supports the territories toward a territorial and polycentric development able to implement European policy at the local level [14]. The PAs organized in NPAs so become intermedium policy actors able to connect local actions with regional and central policies, and to identify cross-border services to share.

Toward meeting this scope, innovative planning tools (including for services) and management that look at the territory in terms of a large area are needed. The European Grouping of Territorial Cooperation (EGTC) is increasingly used to identify the macro-regional services to be carried out in a shared manner [7]:

1. To favor the integrated development of the territories, as spaces in which the life of the citizens takes place;

2. To promote territory-based policies through cross-sectoral policy coordination and a multi-level government system, from local to European levels;

3. To encourage cooperation between territories to strengthen European integration;

4. To improve the knowledge of the territories, in order to guide their development. 
For achieving these goals, a polycentric development approach is able to support and implement territorial cohesion at local and national levels [15]. A network of protected areas (considered as a territorial unit in our case) becomes the large area where public services (national or cross-border) are shared.

The need to integrate policies and to increase the efficiency of services pushes towards a shared management of services in regional, macro-regional, and national (Figure 2) border areas. CPSs contribute to increasing the accessibility to services, providing missing resources, or offering a one-stop-shop and thus yielding a simplification in dealing with a variety of border challenges: to obtain economies of scale for services covering a wider service area than domestic; or economies of scope through the better use of infrastructure investments and operating costs shared among stakeholders in the cross-border region. These appear to be the possible added value of CPS that reflects [16] three aspects:

1. Regional topographic and natural assets and specificities (e.g., environmental CPS, CPS in civil protection and disaster management);

2. High demand for services (e.g., transport CPS; CPS in spatial planning, tourism, and culture; as well as education and training); or

3. Urgent political issues (e.g., healthcare and social inclusion, labor market and employment, citizenship, justice, and public security) or a combination of the three factors.

PAs which are organized in NPAs (formalized/institutionalized or not) can carry out each of the three previous aspects in a shared way.

The NPAs, like CPS, contribute to integration, connectivity (including ecological connectivity), quality of education services, labor market, employment, healthcare, and the implementation of strategic actions to support sustainable policies. However, from the analysis of some experiences of NPAs at different scales (ALPARC, international; Alpi Maritime-Mercantour, transnational; Abruzzo Region, regional; Razlog municipality, urban), only the tool of the EGTC appears able to manage the CPS: the EGTC of Alps Maritime-Mercantour has allowed the sharing of tourist, educational, and biodiversity protection strategies, participation in projects aimed at mitigating climate change, etc., avoiding the unnecessary duplication of costs and supporting the competent authorities in each administrative area.

Sometimes, however, a formal institutional cooperation mechanism such as the EGTC cannot be implemented (the EGTC requires at least two member states or a third country). In such cases, the establishment of a private law body aimed at managing shared services does not appear to be a possible solution (e.g., Abruzzo Region in Italy and Razlog Municipality in Bulgaria). The plurality of competent actors that insist on PA makes it difficult to manage a CPS, because each actor has their own interest and missions. Sometimes the institutional and legislative set-up (often planned in a top-down approach) is not coherent with the territorial need, leading to limits for the development. In contrast, soft governance mechanisms—built using a polycentric approach based on networks-are more flexible, adaptable to different situations/missions/matters, and do not need to be formalized in the institutional context. This appears to be a possible solution to go beyond the limit of territorialism, to be applied particularly when the conditions for EGTC are not met. 


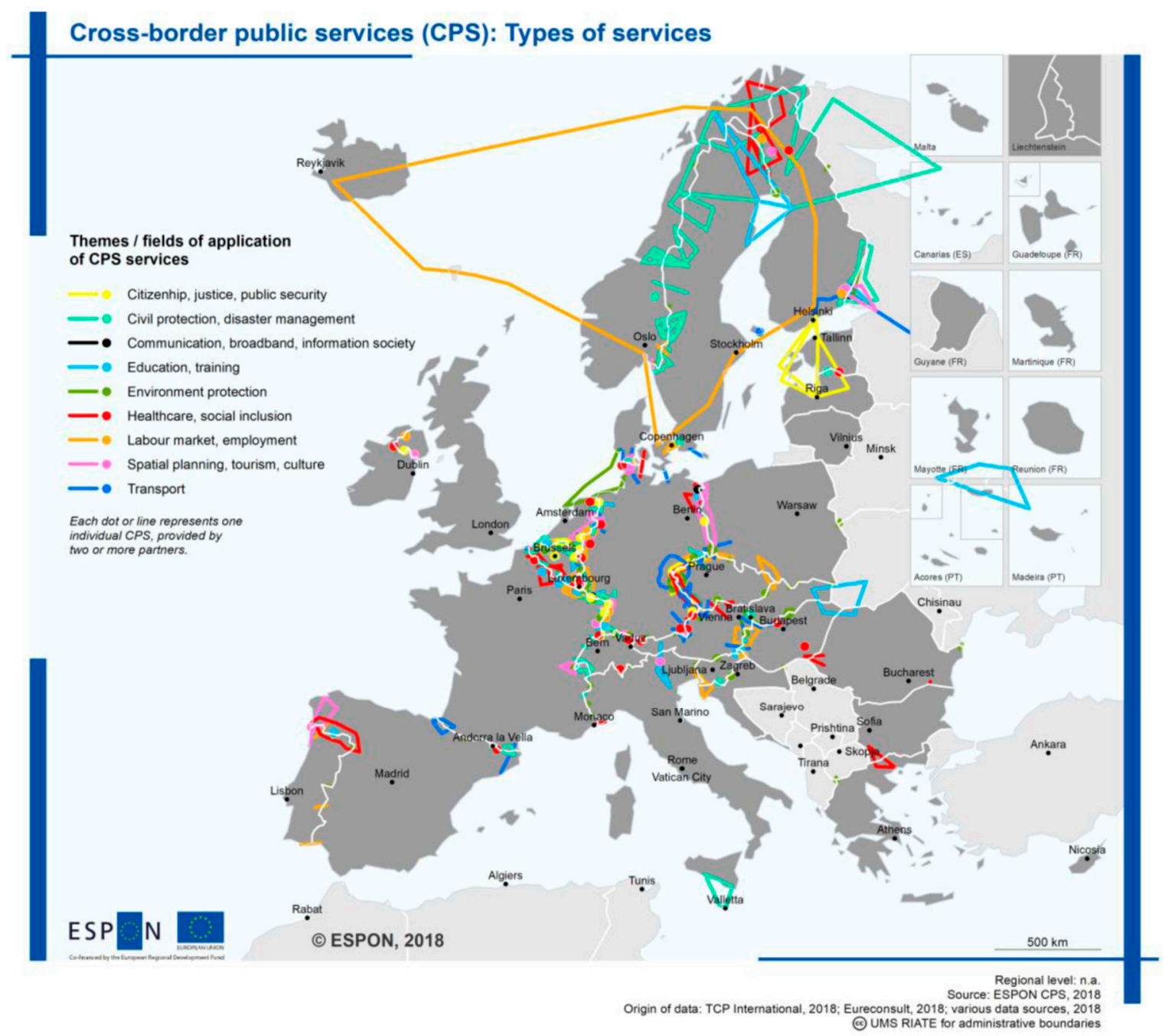

Figure 2. Cross-border public services (CPS): Types of services. Source: ESPON working paper, 2019 , p. 8.

\section{NPA as a Way to Exceed the PA Border towards CPS}

The landscape paradigm [17] suggests the need to look beyond the individual "objects" present in the territory in order to perceive their dynamic and co-evolutionary relationships. Moreover, IUCN's 5th World Parks Congress [10] concluded that PAs should not exist as unique islands, but need to be planned and managed as an integral part of the broader context. From these points of view, the territory can be considered as a "network of networks" able to provide vital connections [18]. A PA works as a system with multidimensional character, and all its relationships in some way influence the connectivity of the systems. This means having not only different protected areas but also different NPA models (international, transnational, regional, and local NPAs) on the basis of the different interactions between protected areas and between protected areas and contexts.

These interactions-formalized or non-formalized-define NPAs as policy instruments (not necessarily leading to new designation-based regulations for PAs), that require coordination and cooperation between PAs within territories and administrative regions [2]. NPAs aim at enhancing the management effectiveness of PAs, harmonizing tools within specific territorial contexts, fostering cooperation among PAs, involving other institutional bodies and stakeholders, and building new partnerships. NPA management and sector development strategies are generally integrated through planning instruments (according to national/regional legislation), which enable an NPA to adopt shared mitigation measures and policies so as to facilitate, in particular, climate change adaptation. 
These strategies are also able to help bio-diversity conservation across Europe, since they respect the specific characteristics of each area and their local identity through the GI implementation proposed as an integral part of spatial planning and territorial development policies-particularly in agriculture, forestry, transport, education, tourism, soil conservation, and water sectors [2].

From this point of view, NPAs are directly linked to the PAs involved, and consequently, in different ways to the municipalities in the area. They have direct connections with central and regional administrative bodies, pay particular attention to international and EU conservation policies (especially $\mathrm{GI}$ ), and have a direct connection with the local actors (economic and/or not).

Therefore, NPAs can interact with the territories where PAs exist, and NPAs become directly linked to the administrative bodies because they work as an "intermedium policy actor" and can be connected with regional and central bodies. By the same token, being intermedium policy actors allows NPAs to connect regional and central bodies with the local bodies where PAs operate.

The networks analyzed in the LinkPAs Project [2] have been divided by geographical scale (international, cross-border, regional, and local), investigating in the four domains common to each model: territorial impact, exchange and cooperation, national and regional policy strategies, and economic resources. In the context of a territorial planning strategy, a general governance model has been developed (Figure 3), where the four common domains are present in all networks.

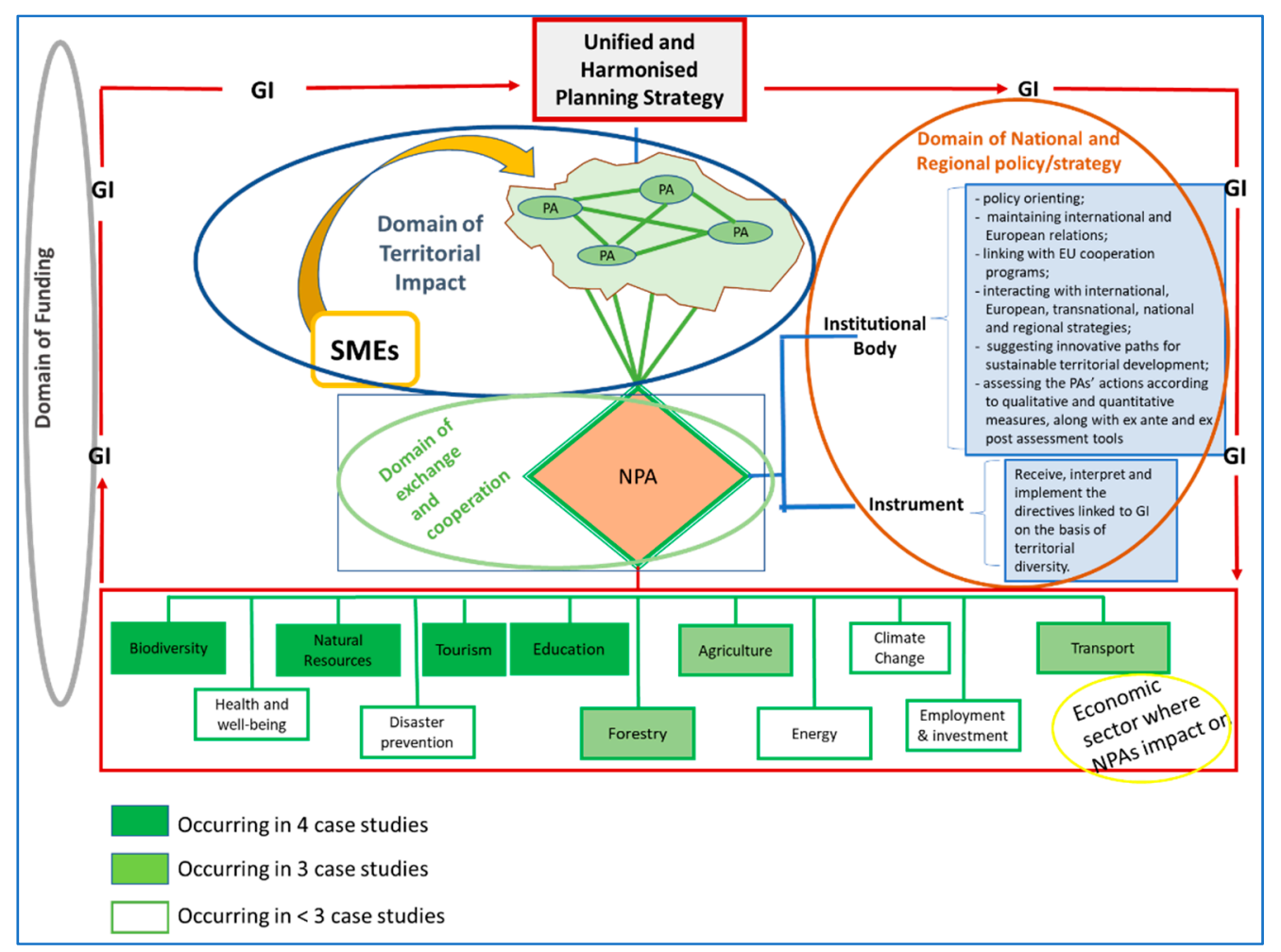

Figure 3. The network of protected areas (NPA) structure according to a unified and harmonized planning strategy framework. Source: ESPON Programme 2020, ESPON LinkPAs, Final Main Report, p. 23.

The relationship between the protected areas at the physical and territorial levels (domain of territorial impact) precedes the formation of the network protected areas and identifies the actions for the implementation of the GI strategies. Protected areas, organized in a network according to a polycentric approach, thus make up the networks (domain of exchange and cooperation). The networks of protected areas are both an institutional body and an instrument of planning and territorial policy (domain of national and regional policy/strategy). This dual role, which represents the domain of national and regional strategy and politics, makes the NPAs political actors for policy orientation, 
maintaining international and European relations; linking with EU cooperation programs; interacting with international, European, transnational, national, and regional strategies; suggesting innovative paths for sustainable territorial development; assessing the PAs actions according to qualitative and quantitative measures, with ex ante and ex post assessment tools. As instruments of planning and territorial policy, the NPAs interpret and implement the directives linked to GI on the basis of territorial diversity. The NPAs are political actors whose choices impact the economic sectors of the green infrastructures strategy: biodiversity, natural resources, tourism, education, agriculture, change, transport, health and well-being, disaster protection, forestry, energy, employment, and investment. The economic sectors impacted by NPAs have different weights (from white to dark green in Figure 3) and are a function of the services that the PAs decide to carry out in a shared way. The entire process involves the domain of funding linked to the objectives and aims of the NPA (and policies).

Some economic sectors impacted by NPAs are part of the cross-border public services generally shared at the EU level. From the combination of types of services shared at the EU level with the GI sectors impacted by NPAs, it is evident which sectors are shared with both (GI and CPS) (Figure 4). This means that some sectors can be implemented in a shared way because they are already in common with both strategies. At international and transnational levels they could be implemented by the EGTC, but at subnational and local levels they need to work as a network in order to produce economy of scale and/or scope. The NPA management model implemented in LinkPAs could be the instrument to achieve this goal.

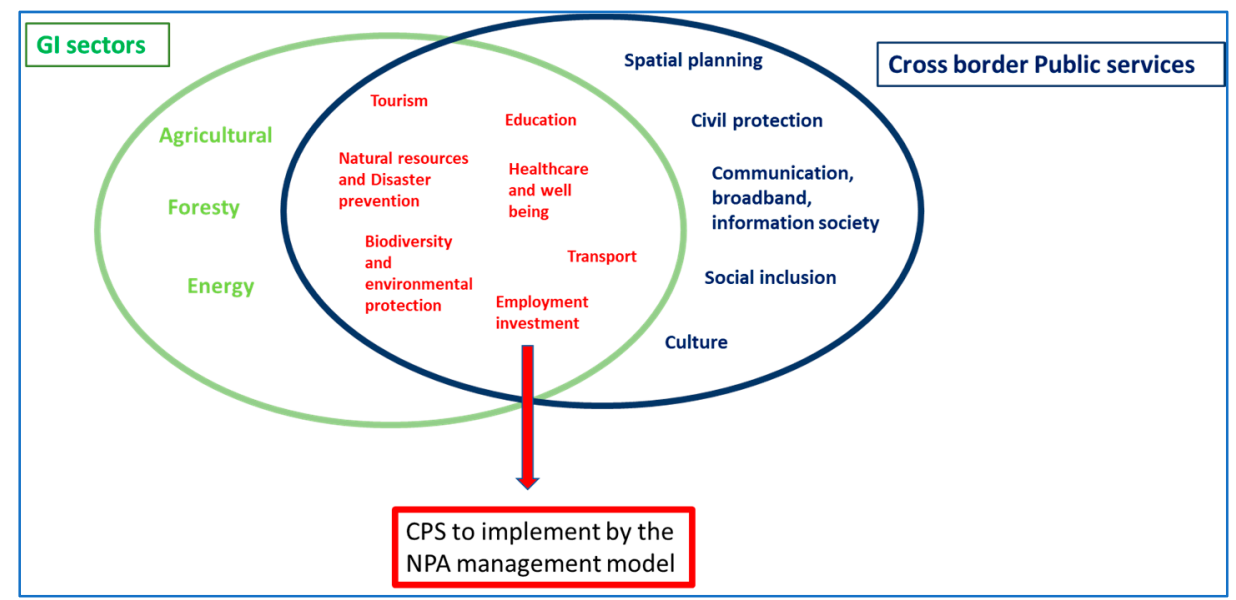

Figure 4. CPS to implement by the NPA management model. Source: Elaborated by the Autor. GI: green infrastructure.

An instrument particularly suited to the financing part is integrated territorial investment (ITI), whose transcalar and flexible nature makes it possible, through the combination of several funds, to finance complex, multi-purpose, and multi-dimensional projects.

\section{Remarks}

In PAs, territorial diversity appears to be crucial for sustainable and polycentric spatial planning mechanisms, becoming the starting point for an efficient and sustainable development strategy able to increase territorial cohesion. PAs represent one of the poles of polycentric development strategy. The relationship system between the PAs is crucial to assess the impacts of the implementation of green infrastructure strategies and to identify which CPS to share: the PAs organized in NPAs become the intermedium policy actor to achieve European and local goals. In particular, the PAs (considered as the territorial unit for the territorial development) working as NPAs are able to influence and shape territorial development by: (1) influencing regional or national policies; (2) exchanging knowledge and experiences; (3) obtaining funding to develop projects. 
In order to extend beyond their borders, NPAs work as macro-regions according to formal or informal participatory agreements involving the PAs (territorial unit) in order to better understand the territorial needs and facilitate the implementation of activities at the local level in a polycentric way.

The networks of protected areas appear as a flexible tool for developing, harmonizing, and unifying sustainable development planning strategies. They can provide appropriate territorial solutions in the context of biodiversity and nature conservation, and in the adaptation and mitigation of climate change. The flexible and transcalar nature of the network makes it compatible with a plurality of sectoral policies, and therefore favors a virtuous process of territorial cooperation. The recognition of the networks of protected areas as actors and policy tools would create the still-missing link between the territorial unit of the "protected area", the sectoral policies, and the overall strategy of territorial planning. In this sense, NPAs are intermedium policy actors.

The different economic sectors impacted by NPAs in common at the CPS are currently shared at the EU level. This means that there is already a strategy to build CPS at international and transnational levels (also through the EGTC), but this is still missing at regional and local levels. The NPA management models could be a way to identify and implement shared public services at the subnational level.

Author Contributions: Although in unity of purpose, the paper's conceptualization (paragraphs 1 and 5) is attributed to M.P., while the formal analysis (paragraphs 2, 3, and 4) is attributed to M.C.

Funding: This research was funded by ESPON Programme 2020, EE/SO2/033/2017.

Acknowledgments: ESPON 2020 Programme. A special Acknowledgment to the ESPON LinkPAs project partners: University of Tor Vergata, IT (lead contractor); University of Camerino, IT; European Academy of Bozen-Bolzano-Eurac Research, IT; C.O. Institute of Ecology, AT; UMR Espace CNRS, FR; Forest Research Institute, BG.

Conflicts of Interest: The authors declare no conflict of interest.

\section{References}

1. Faludi, A. The poverty of territorialism: Revisiting European spatial planning. disP Plan. Rev. 2016, 52, 73-81. [CrossRef]

2. ESPON Programe 2020 Programme. LinkPas-Linking Networks of Protected Areas to Territorial Development-ESPON LinkPAs; Main Report; ESPON Programe 2020 Programme: Luxemburg, 2018; Available online: https://www.espon.eu/protected-areas (accessed on 24 August 2019).

3. Davoudi, S. From "left behind" to "kept behind" places: Re-imaging territorial cohesion. In Proceedings of the Functional Areas and Territorial Cohesion in ESPON Seminar, Iasi, Romania, 19-20 June 2019.

4. Bennett, G. Integrating Biodiversity Conservation and Sustainable Use: Lessons Learned from Ecological Networks; IUCN: Gland, Switzerland; Cambridge, UK, 2004; ISBN 2-8317-0765-X.

5. IUCN. Guidelines for Applying Protected Area Management Categories; IUCN: Gland, Switzerland, 2013; Available online: https://cmsdata.iucn.org/downloads/iucn_assignment_1.pdf (accessed on 1 October 2018).

6. European Commission. GREEN PAPER on the Modernisation of EU Public Procurement Policy towards a More Efficient European Procurement Market. 2011. Available online: https://eur-lex.europa.eu/LexUriServ/ LexUriServ.do?uri=COM:2011:0015:FIN:EN:PDF (accessed on 24 August 2019).

7. Regulation (EC) 1082/2006; European Grouping of Territorial Cooperation (EGTC). Available online: https: //eur-lex.europa.eu/legal-content/EN/TXT/?uri=CELEX:32006R1082 (accessed on 24 August 2019).

8. Davoudi, S. Polycentricity: What Does It Mean and How Is It Interpreted in The ESDP? In Proceedings of the EURA Conference Urban and Spatial European Policies: Levels of Territorial Government, Turin, Italy, 18-20 April 2002.

9. Prezioso, M. Quale Territorial Impact Assessment Della Coesione Territoriale Nelle Regioni Italiane. La Concettualizzazione del Problema; Patron: Bologna, Italy, 2008.

10. Benefits Beyond Boundaries. Proceedings of the Vth IUCN World Parks Congress. Available online: https://portals.iucn.org/library/sites/library/files/documents/2005-007.pdf (accessed on 1 October 2018).

11. European Commission (EC). An Action Plan for Nature, People and the Economy. 2017. Available online: http://ec.europa.eu/environment/nature/legislation/fitness_check/action_plan/communication_en.pdf (accessed on 1 October 2018). 
12. European Commission (EC). EU Biodiversity Strategy to 2020. 2010. Available online: http://ec.europa.eu/ environment/nature/info/pubs/docs/brochures/2020\%20Biod\%20brochure\%20final\%20lowres.pdf (accessed on 1 October 2018).

13. Feldman, D.L. The future of environmental networks-Governance and civil society in a global context. Futures 2012, 44, 787-796. [CrossRef]

14. Coronato, M. The contribution of cities network to Europeanization process. In The Case of Environmental Policies-Atti XXXII Congresso Geografico Italiano; AGEI: Roma, Italy, 2019; pp. 2627-2632.

15. Davoudi, S. EUROPEAN BRIEFING: Polycentricity in European spatial planning: From an analytical tool to a normative agenda. Eur. Plan. Stud. 2003, 11, 979-999. [CrossRef]

16. ESPON Programe 2020. ESPON Cross Public Services, Working Paper. 2019. Available online: https: //www.espon.eu/cps-brief (accessed on 24 August 2019).

17. Council of Europe. European Landscape Convention 2000. Available online: http://www. convenzioneeuropeapaesaggio.beniculturali.it/uploads/Council\%20of\%20Europe\%20-\%20European\% 20Landscape\%20Convention.pdf (accessed on 1 October 2018).

18. Bulkeley, H.; Kern, K. Cities, Europeanization and Multi-level Governance: Governing Climate Change through Transnational Municipal Networks. JCMS 2009, 47, 309-332.

(C) 2019 by the authors. Licensee MDPI, Basel, Switzerland. This article is an open access article distributed under the terms and conditions of the Creative Commons Attribution (CC BY) license (http://creativecommons.org/licenses/by/4.0/). 